TAO, Vol. 11, No. 3, 581-590, September 2000

\title{
Relocation of the 1999 Chi-Chi Earthquake in Taiwan
}

\author{
Chien-Hsin Chang ${ }^{1,2,{ }^{*}, \text { Yih-Min Wu}}{ }^{1}$, Tzay-Chyn Shin ${ }^{1}$ and Chien-Ying Wang ${ }^{2}$
}

(Manuscript received 31 March 2000, in final form 15 June 2000)

\begin{abstract}
The 1999 Chi-Chi earthquake in Taiwan represented the island's largest inland seismic event of the last century. This earthquake severely struck the western-middle part of the island. Abundant high-resolution digital seismic data were recorded by two seismic networks operated by the Central Weather Bureau (CWB). In this paper, we combined data from two CWB seismic networks to analyze the characteristics of the Chi-Chi earthquake sequence. The mainshock was relocated to $23.853^{\circ} \mathrm{N}, 120.816^{\circ} \mathrm{E}$ at the depth of $8 \mathrm{~km}$. The focal mechanism was of a thrust type with strike $5^{\circ}$, dip $34^{\circ}$ and rake $65^{\circ}$ based on the new location and the first motion polarities. The distribution of the aftershocks revealed a special distribution pattern which marked out an aseismic dipping plane with the aftershocks mostly occurring on its upper side. It is highly suggested that there is a close relationship between this aseismic dipping plane and the Chelungpu fault .
\end{abstract}

(Key words: Chi-Chi earthquake, Epicenter relocation, Aftershocks)

\section{INTRODUCTION}

At 1:47 a.m., September 21, 1999 (17:47 UTC, September 20, 1999), a major earthquake $\left(\mathrm{M}_{\mathrm{L}}=7.3\right.$ or $\mathrm{M}_{\mathrm{W}}=7.6$ ) occurred near the town of Chi-Chi in Nantou county in central Taiwan, about $150 \mathrm{~km}$ to the south of Taipei. This earthquake marked the largest inland seismic event of the twentieth century in Taiwan. At the end of 1999, Taiwan's Interior Ministry reported that the death toll was 2,412 , and the number of injured stood at 11,305 . Thousands of houses collapsed, and more than 100,000 people were left homeless. This disastrous earthquake, however, generated a wealth of high-resolution seismic digital data which provided us with an unprecedented opportunity to study a large earthquake event from a close distance. This valuable data set was collected by the two seismic networks operated by the Central Weather Bureau (CWB), which includes the CWB Seismic Network (CWBSN) with 73 real

\footnotetext{
${ }^{1}$ Central Weather Bureau, Taipei, Taiwan, ROC

${ }^{2}$ Institute of Geophysics, National Central University, Chung-li, ROC

* Corresponding author address: Dr. Chien-Hsin Chang, Central Weather Bureau, 64 Kung-Yuan Road, Taipei, Taiwan, ROC; E-mail: gensin @taiwan.cwb.gov.tw
} 
time weak motion and strong motion stations and the Taiwan Strong Motion Instrumentation Program (TSMIP) with 600 stand-alone strong motion stations all over the island. It is insightful to explore earthquakes in still greater detail by combining the data from these two relatively independent seismic networks.

The accuracy of earthquake location mainly depends on the quality of seismic-wave arrivals, the spatial distribution of recording stations, the methodology used to locate an earthquake, and the crustal and upper mantle velocity model employed. The inter-station spacing of the CWBSN and the TSMIP stations are about $30 \mathrm{~km}$ and $5 \mathrm{~km}$, respectively. The CWBSN is an evenly distributed, real-time and central recording system equipped with 3-component $S$ 13 seismometers, some of which are co-sited with a 3-component accelerometer. The TSMIP, on the other hand, is a trigger-type stand-alone strong motion system (using accelerometers A900, A900A, IDS and ETNA) which are deployed mostly within the major metropolitan areas of the island. Some TSMIP stations have GPS timing. In this study, we relocated the Chi-Chi mainshock by combining the data recorded by the CWBSN and the TSMIP stations. This not only increased the quantity of arrival-time data, but also provided extra station coverage, thereby upgrading the accuracy of earthquake sites as well as their focal mechanisms. These more accurate and detailed aftershock locations can further be used to reveal a better picture of the anomalous seismic activity related to seismogenic tectonics.

\section{RELOCATION OF THE MAINSHOCK AND ITS FOCAL MECHANISM}

Taiwan is situated at the junction of the Ryukyu Island Arc and the Philippine Island Arc. The Philippine Sea plate subducts northward under the Eurasian plate along the Ryukyu Trench offshore eastern Taiwan, and the South China Sea plate subducts eastward under the Philippine Sea plate at the southern tip of the island. The interactions between the continent and the arcs have resulted in a very complicated crustal structure in the Taiwan region. This complex and not so well-known velocity structure has the potential of causing large uncertainties as to earthquake locations. To improve the accuracy in this regard, we relocated the Chi-Chi mainshock using the data recorded at the near-source CWBSN and TSMIP stations. Better and denser station coverage gave us the opportunity to greatly improve in location accuracy.

Data from six CWBSN stations and twelve TSMIP stations (Fig. 1) were used to relocate the Chi-Chi mainshock. Since the TSMIP stations are not equipped with a unified time system, only S-P time differences from these stations were involved in the determination of the earthquake location. However, the CWBSN system has unified timing, but with such a limited dynamic range that almost all $\mathrm{S}$ phases are clipped. Fortunately, five of the six CWBSN stations have strong enough motion instruments co-sited for reliable $S$ arrivals to be preserved. The 1-D layered velocity model of Shin and Ho (1994) was adopted in this study (Fig. 1). This velocity model is determined from an inversion of thousands of seismic data sets generated from previous earthquakes in western Taiwan (Shin and Ho 1994) and is considered applicable to the Chi-Chi earthquake region.

The layered model and the Geiger's method were employed to relocate the mainshock. The hypocenter was relocated to $23.853 \sqrt{\mathrm{N}}, 120.816[\mathrm{E}$ with a focal depth at $8 \mathrm{~km}$. On the basis 


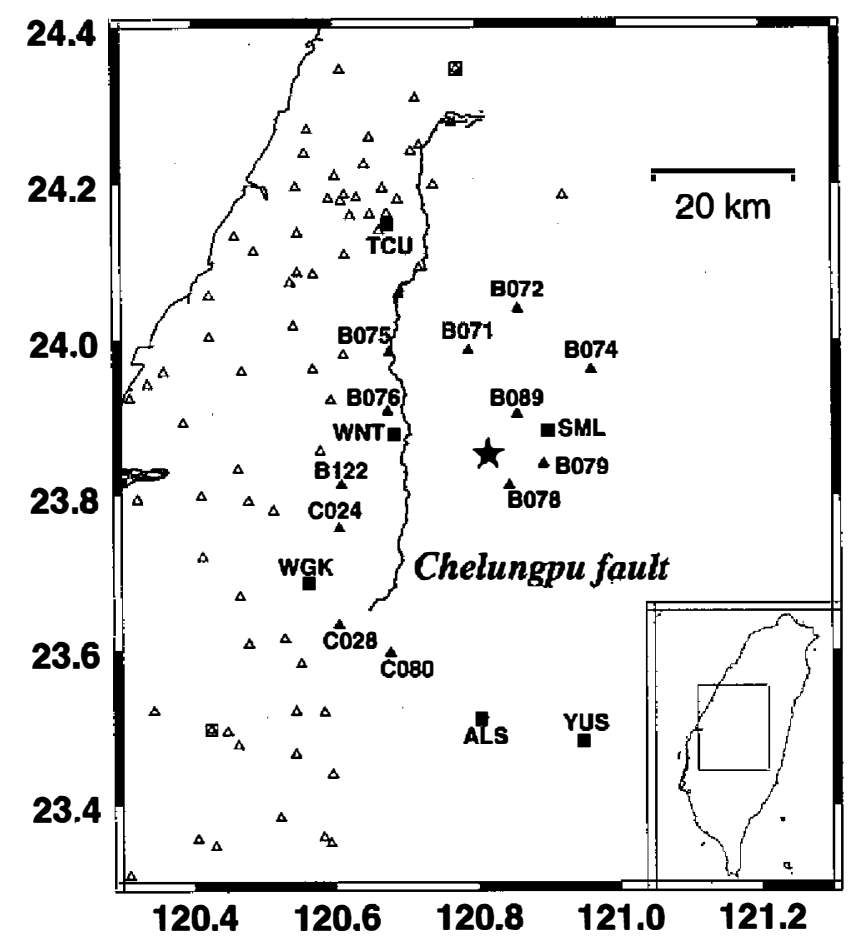

(a)

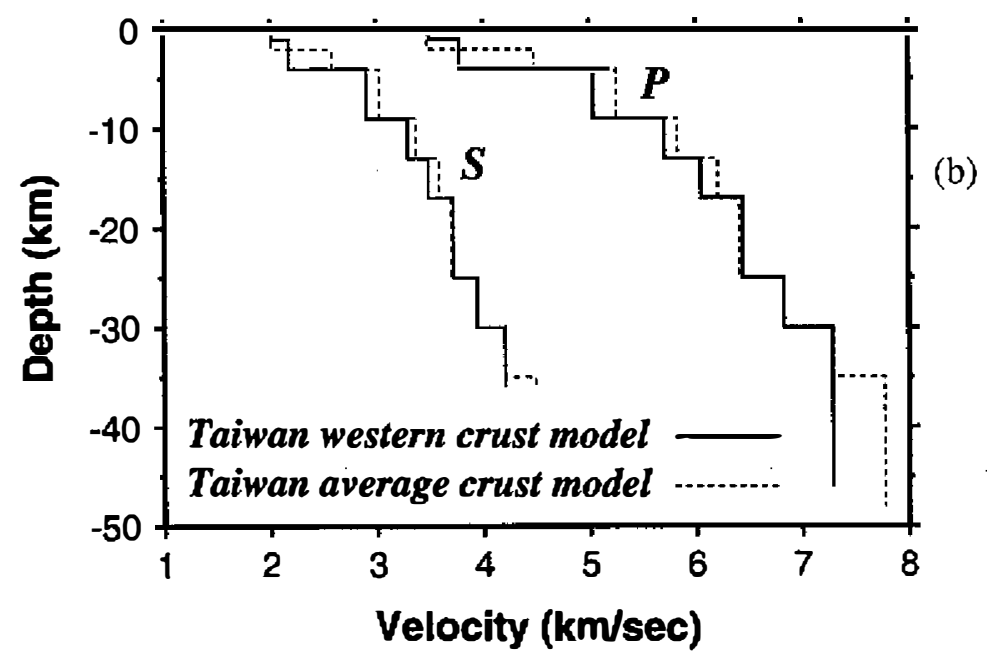

Fig. 1. (a) Station distribution of the Central Weather Bureau Seismic Network (CWBSN; squares) and the Taiwan Strong Motion Instrumentation Program (TSMIP; triangles) in central Taiwan. The stations used to determine the mainshock's location are denoted with the station names. (b) Velocity model used in this study (solid lines; Shin and Ho 1994) and the Taiwan average crust model (dashed lines; Chen and Shin 1998). 
of three statistical error measurements, i.e., the root-mean-square (RMS) of travel time residuals, the error in depth (ERZ) and the error in epicenter (ERH; Flinn 1965) calculated for the depths from 1 to $16 \mathrm{~km}$ (Fig. 2), we found that the source depth of $8 \mathrm{~km}$ was apparently the best solution. When we replaced the velocity model with the Taiwan average crust model (Chen and Shin 1998), the best focal depth moved to $10 \mathrm{~km}$ (Fig. 2). Comparing the three statistical error estimates RMS, ERH and ERZ using the two different velocity models, we

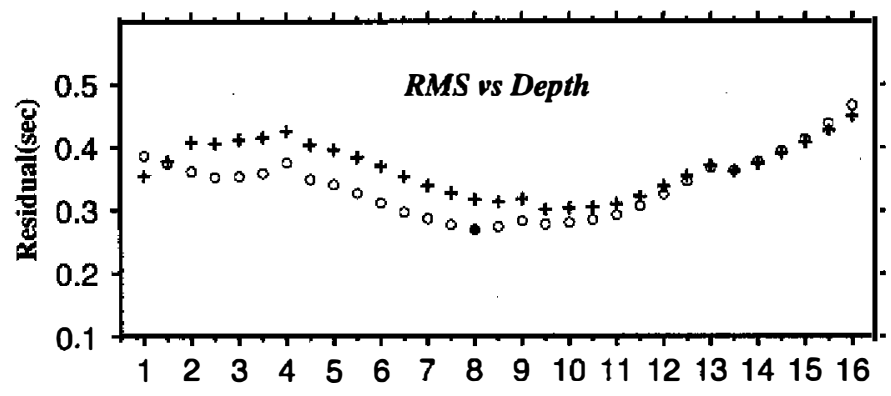

(a)

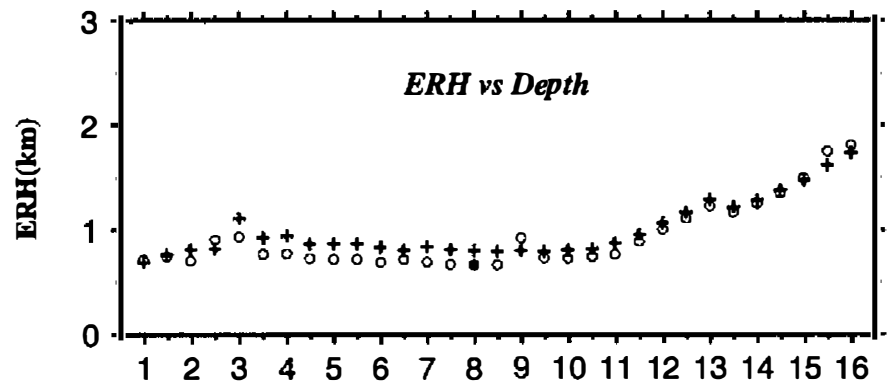

(b)

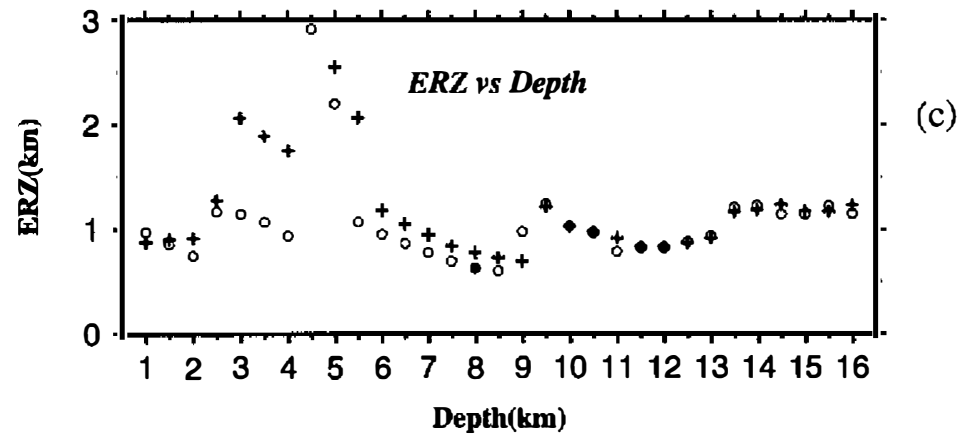

Fig. 2. Error analysis for determining the mainshock's location: (a) RMS (travel time residuals); (b) ERZ (the error in depth); and (c) ERH (the error in epicenter). They were calculated for depths from 1 to $16 \mathrm{~km}$ using two different velocity models. The crosses indicate the results from the model of Chen and Shin (1998) which is an average of Taiwan island. The open circles represent the results from the model of Shin and Ho (1994) which is a local model designed for central Taiwan. Solid circles represent the best results in this study. 
could conclude that the model of Shin and Ho (1994) was probably more suitable than the Taiwan average model for the study region. Figure 3 shows the travel time plot of the nearsource CWBSN seismograms and the TSMIP accelerograms of the mainshock based on the new source location. In this figure, every trace was placed in the right position of the epicentral distance measured from the newly-determined epicenter. The TSMIP accelerograms which

Original Time(UT):1999/09/20 17:47:15.85 Location: $23.853^{\circ} \mathrm{N} 120.816^{\circ} \mathrm{E}$ Depth:8km

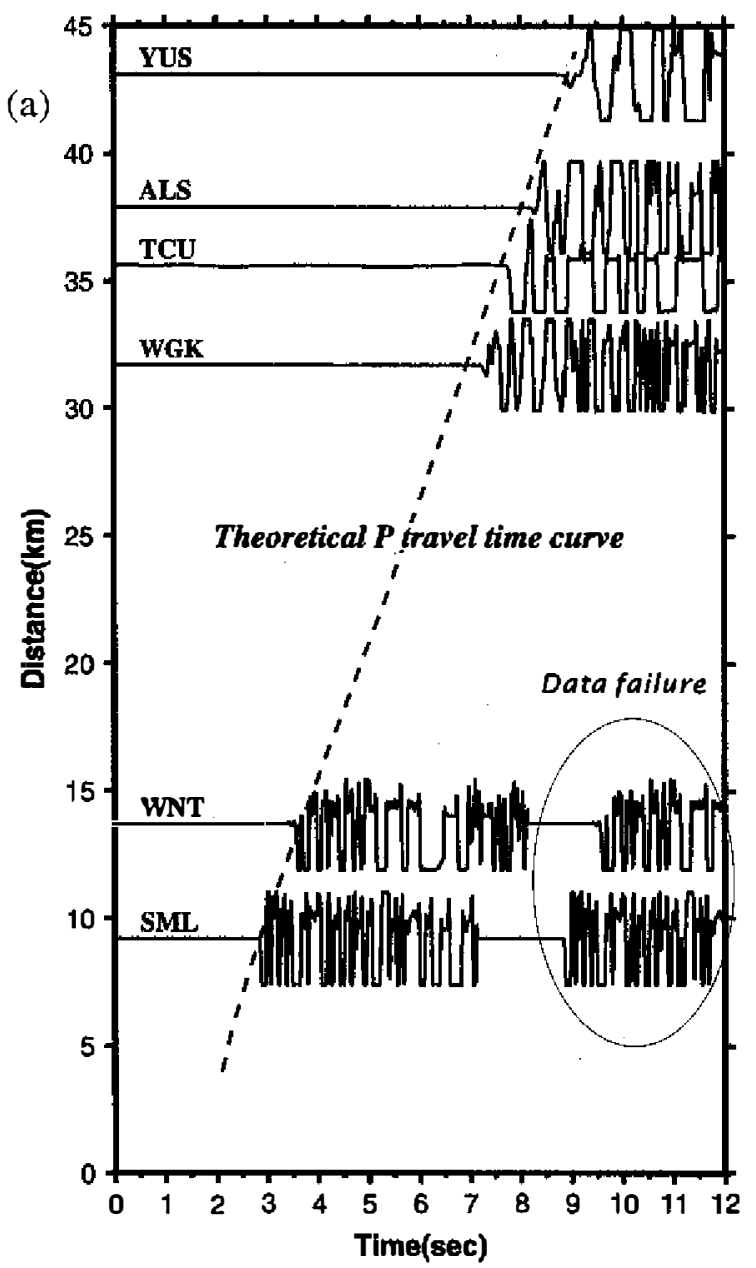

(b)

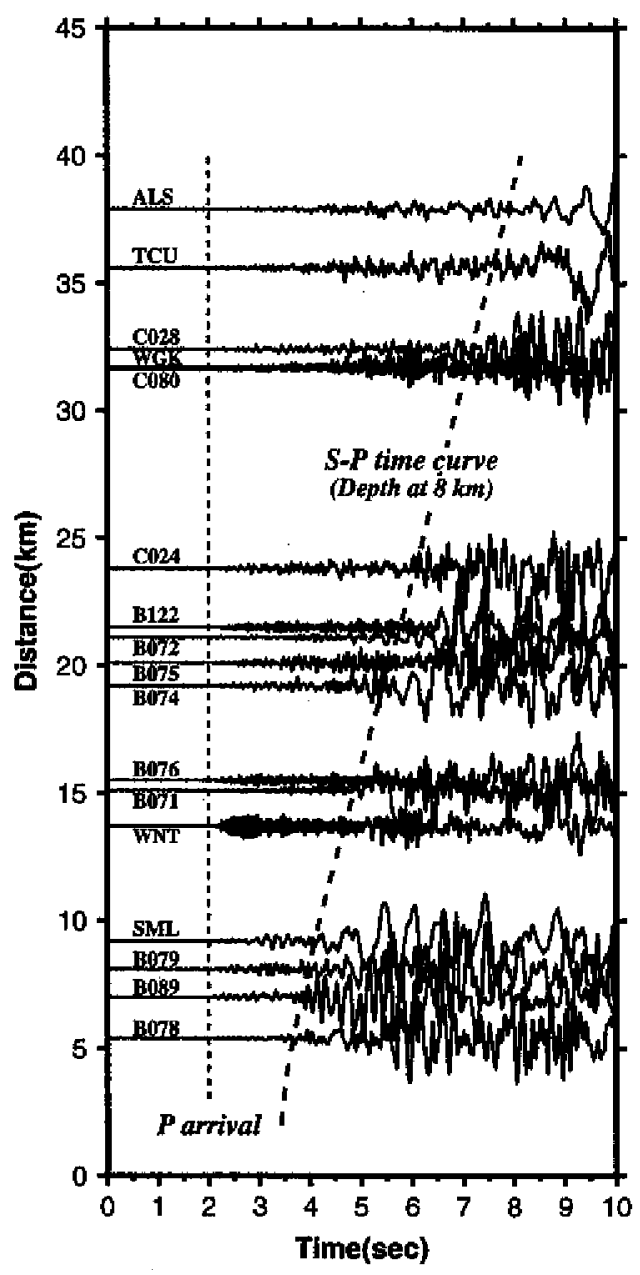

Fig. 3. Seismograms used for the earthquake relocation in this study. (a) velocity seismograms of the vertical component for the CWBSN; (b) accelerograms of the horizontal component records by the TSMIP. These traces are displayed at proper positions given by their epicentral distances. Their P-arrivals were lined up and the S-arrivals were denoted by a slanted line. 
the $\mathrm{P}$ arrivals were aligned, and a theoretical $\mathrm{S}$-wave travel-time curve was calculated from the relocated hypocenter, as shown. The agreement between the S-wave arrivals and the theoretical travel-time curve suggests that the relocated mainshock hypocenter is in fact reliable.

Using the new source location and the first P polarities from the CWBSN and the TSMIP stations, we reexamined the focal mechanism. The focal mechanism (Fig. 4) was a thrust type with strike $5^{\circ}$, dip $34^{\circ}$ and rake $65^{\circ}$, which is consistent with the observed surface ruptures along the Chelungpu fault. The P-axis at the strike $293^{\circ}$ and the plunge angle of $13^{\circ}$ both agree with the background tectonics in which the Philippine Sea plate collides with the Eurasian

\section{Fault Plane solution of the Chi-Chi event}

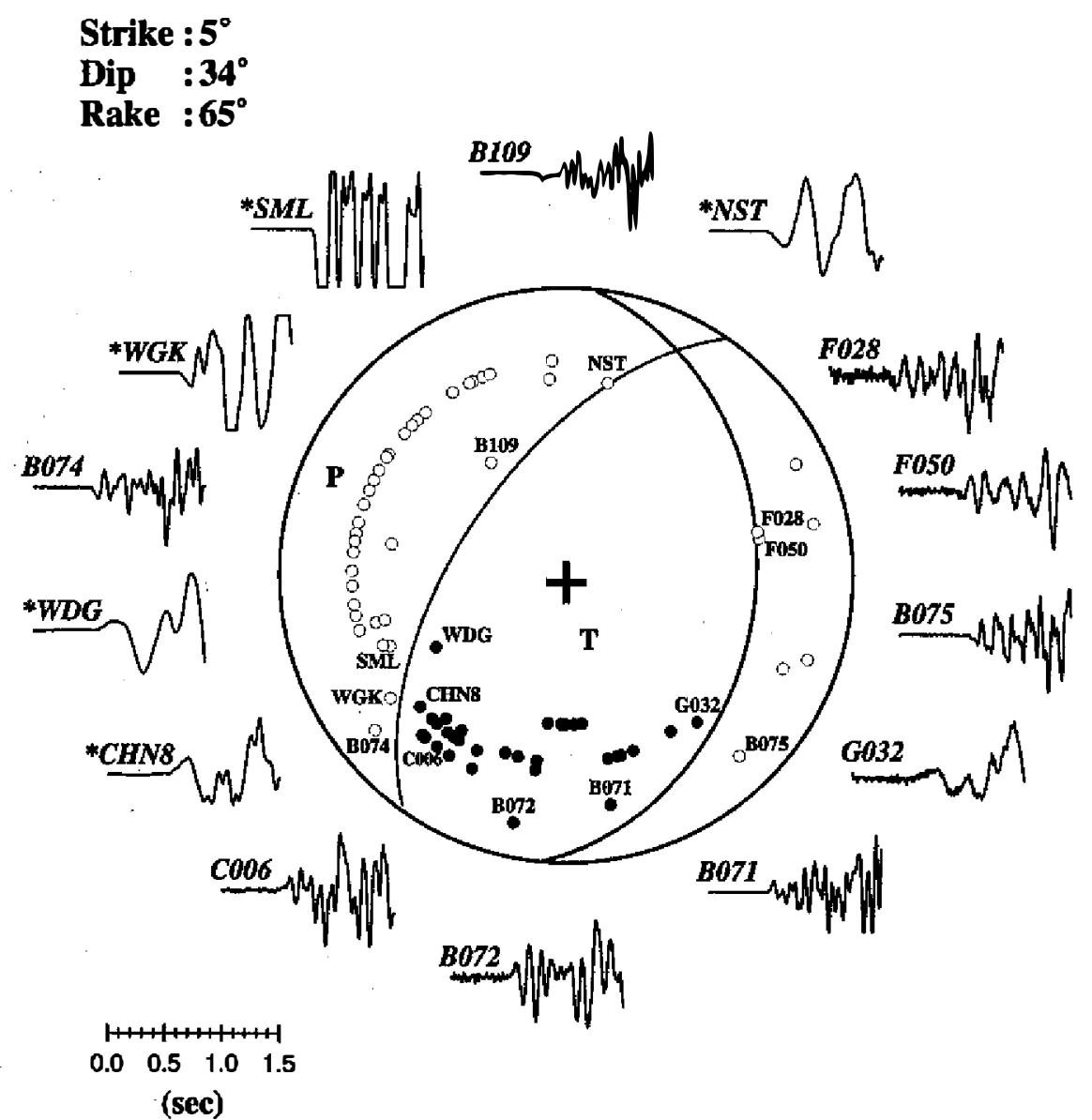

Fig. 4. Focal mechanism of the Chi-Chi mainshock determined after the hypocenter relocation and the pickup of the senses of first $P$ motions from the stations around the center. Station codes with stars are those from CWBSN records, while the others are from the TSMIP. 
plate in the northwestern direction. Figure 4 also includes several first $\mathrm{P}$ motions near the nodal planes, which offer good constraints to 'narrow down' the fault plane. All of the first $P$ motion polarities agree with this focal mechanism, which strongly supports the notion that the focal mechanism established in this study is in good control and that the source location must have been reliably determined.

\section{AFTERSHOCK DISTRIBUTION}

The aftershocks of the Chi-Chi earthquake lasted for more than six months and amounted to over 20,000 events, according to records from the CWBSN. The Chi-Chi earthquake induced apparent surface ruptures of more than $85 \mathrm{~km}$ along the Chelungpu fault. However, the aftershocks covered an area as broad as $150 \mathrm{~km}$ long and $100 \mathrm{~km}$ wide, which is much larger than the faulted area. Figure 5 shows the epicentral distribution of the Chi-Chi aftershocks which covers almost half of Taiwan island. Most aftershocks distribute on the eastern side of the Chelungpu fault. Significant here is that the surface rupture fault area is characterized by low aftershock activities. The energy accumulated on the Chelungpu fault must have been completely released by the mainshock, but only a small number of aftershocks occurred in the same area. A strong explanation for this strange pattern of aftershock distribution has been given by Wang et al. (2000), and this is based on the thin-skinned thrust model (Suppe 1980). The Hsuehshan Range belt (III in Fig. 5) had high aftershock seismicity, the Backbone Range belt (II in Fig. 5) had low seismicity, and the Tailuko metamorphic belt (I in Fig. 5) regained high aftershock activity. Figure 6 shows four profiles (AA', BB', CC' and DD') extracted from Fig. 5. The aftershocks deviated to the east of the Chelungpu fault, and a plane almost lacking in aftershocks can even be drawn beneath the surface rupture across the profiles as indicated by the broad gray lines in Fig. 6. Most aftershocks occurred above this aseismic plane. If the detachment surface of the thin-skinned model does exist, this dipping aseismic plane must be a good candidate. The low aftershock activity under the Backbone Range belt can be attributed to the high thermal gradient (Wu et al. 1997) or the intrusion of fluid (Chen and Chen 1998). In fact, the distribution pattern of the Chi-Chi aftershocks is similar to previous seismicity which has occurred in the past 100 years in this region, as reported by Wang and Shin (1998).

\section{DISCUSSION AND CONCLUSIONS}

The relocated epicenter is about $5 \mathrm{~km}$ away from the first preliminary epicenter reported by the CWB Taiwan Rapid Earthquake Information Release System (RTD; Wu et al. 2000). The RTD report was automatically generated within the first 100 seconds after the commencement of the mainshock. Since the Chi-Chi mainshock caused large scale electric power supply failure, most real-time seismic stations in northern Taiwan (CWBSN) were out of function at this important moment. Only 13 stations with epicentral distances of more than $30 \mathrm{~km}$ could be used by the RTD to determine the preliminary location of the mainshock. The $5 \mathrm{~km}$ difference between the relocated and the RTD locations is understandable. 


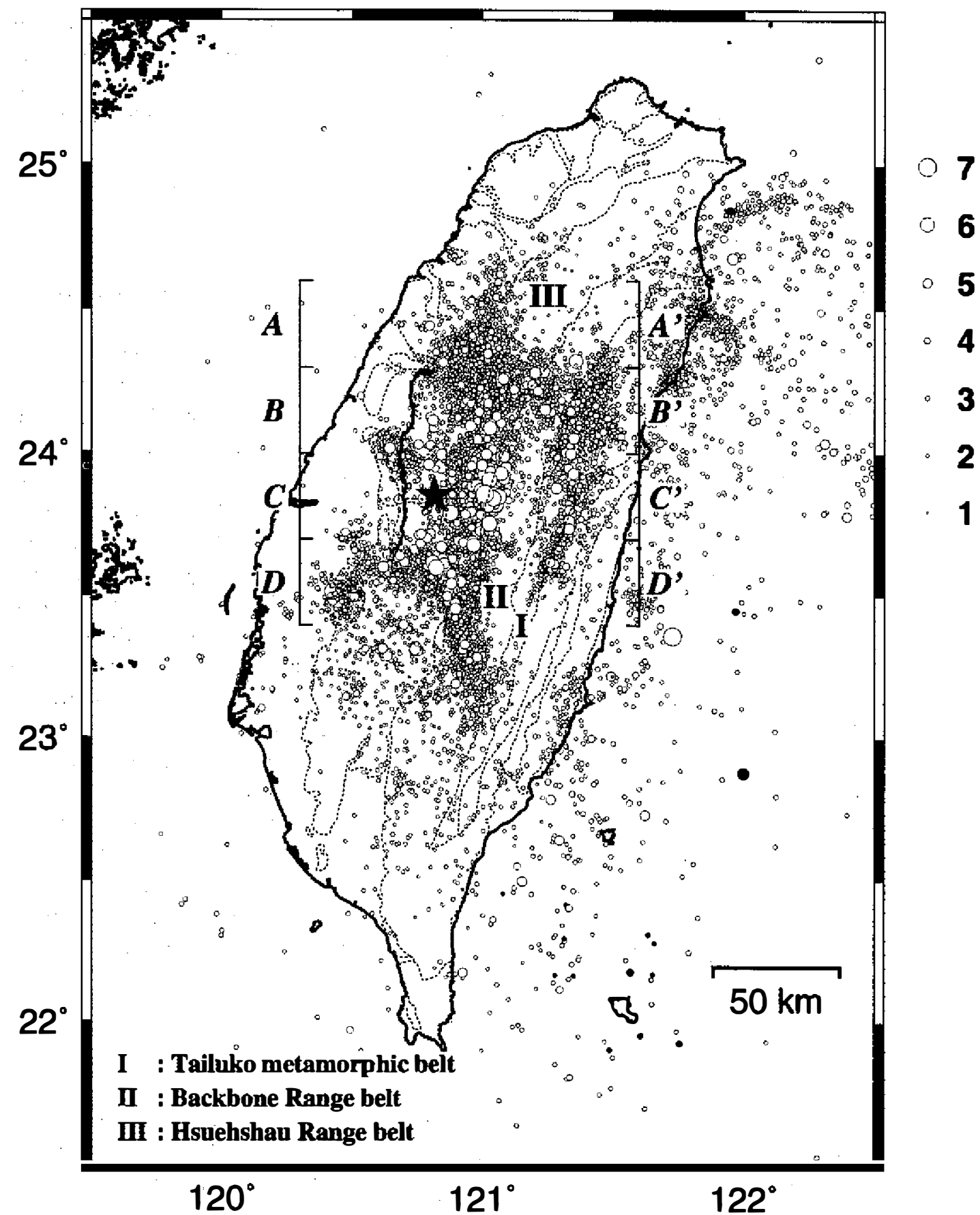

Fig. 5. Map showing the distribution of the Chi-Chi aftershocks. Different geological units are also indicated: I for the Tailuko metamorphic belt; II for the Backbone Range belt; and III for the Hsuehshau Range belt. 

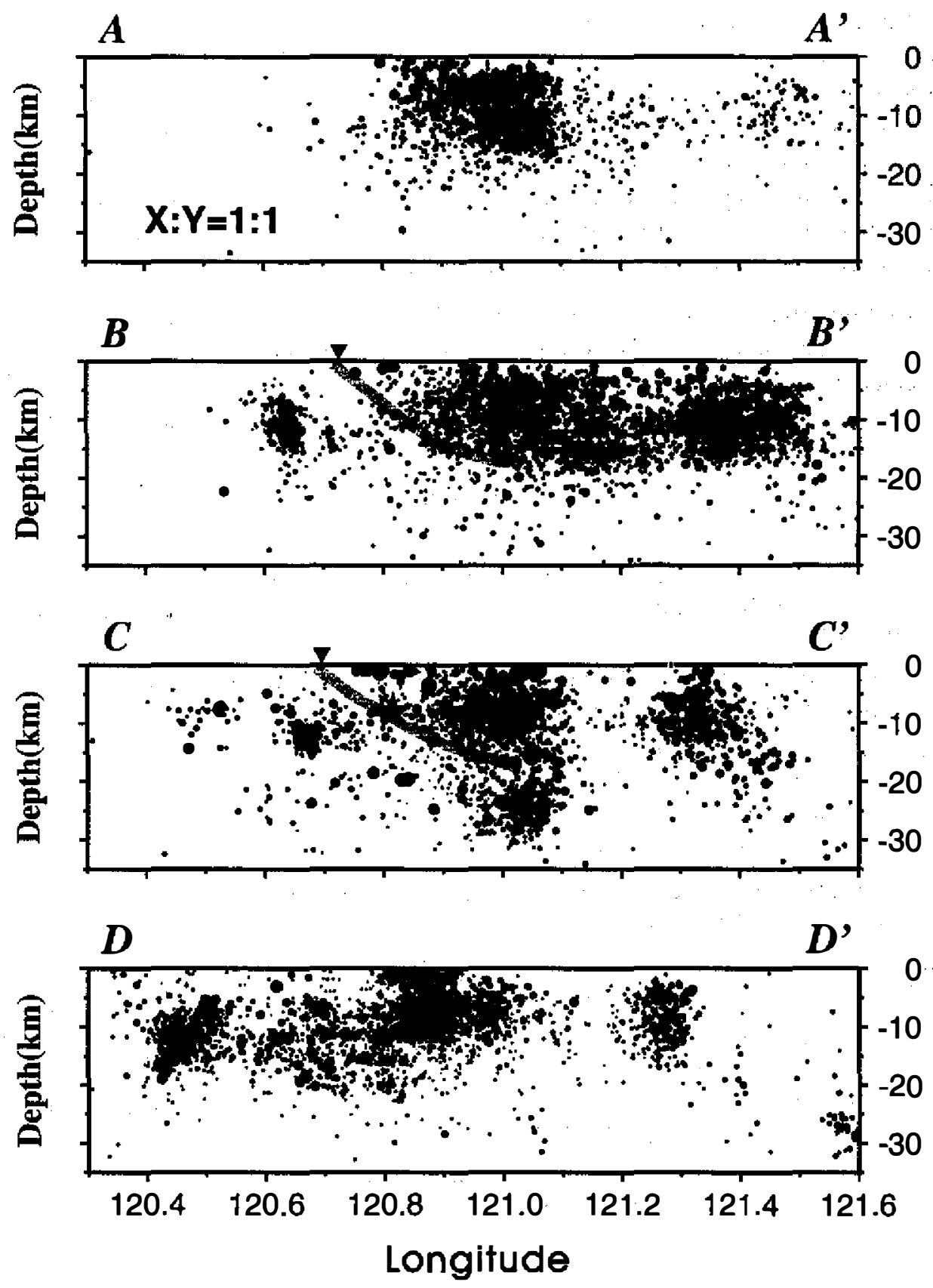

Fig. 6. Four profiles of the Chi-Chi aftershocks as indicated in Fig. 5. The star in Profile $C$ is the location of mainshock. The surface position of the Chelungpu fault is denoted by a small inverted triangle(Profiles B and C). The Broad gray lines in Profiles B and $\mathrm{C}$ show the possible underground fault traces. Most aftershocks occurred above this fault trace. 
In this paper, we relocated the Chi-Chi earthquake in Taiwan and investigated its characteristics. We used near source $\mathrm{P}$-arrivals and S-arrivals and S-P time differences to relocate the mainshock to $23.853^{\circ} \mathrm{N}, 120.816^{\circ} \mathrm{E}$ with a focal depth of $8 \mathrm{~km}$. The focal mechanism of the main shock was a thrust type with a fault plane solution (strike $5^{\circ}$, dip $34^{\circ}$ and rake $65^{\circ}$ ) determined from the first $\mathrm{P}$ motion polarities of the CWBSN and TSMIP recordings. The distribution of the aftershocks can be traced with a lack-aftershock dipping plane such that most of the aftershocks occurred above this plane. Most aftershocks occurred in the Hsuehshan Range belt, with only a few in the Backbone Range.

Acknowledgments This research was supported by the Central Weather Bureau. Countless hours of labor devoted by the CWB staff to locate the aftershocks within the endless flood of complicated wave pulses are highly appreciated. We are also grateful to Dr. Y. B. Tsai, Dr. J. M. Chiu, Dr. Z. S. Liaw and Dr. W. Lucas and the reviewers for their valuable suggestions.

\section{REFERENCES}

Chen, C. C., and C. S. Chen, 1998: Preliminary result of magnetotelluric soundings in the fold-thrust belt of Taiwan and possible detection of dehydration. Tectonophys., 292, 101-117.

Chen, Y. L., and T. C. Shin, 1998: Study on the earthquake location of 3-D velocity structure in the Taiwan area. Meteo. Bull., 42, 135-169.

Flinn, E. A., 1965: Confidence regions and error determinations for seismic event location. Rev. of Geophy., 3, 157-185.

Shin, T. C., and M. Y. Ho, 1994: Three dimensional velocity structure of western Taiwan. Meteo. Bull., 40, 216-234.

Suppe, J., 1980: Imbricated structure of western foothill belt, south-central Taiwan. Petro. Geol. Taiwan, 17, 1-16.

Wang, C. Y., and T. C. Shin, 1998: Illustrating 100 years of Taiwan seismicity. TAO, 9, 589614.

Wang, C. Y., C. H. Chang, and H. Y. Yen, 2000: An interpretation of the 1999 Chi-Chi earthquake, Taiwan based on the thin-skinned thrust model. TAO, (this issue)

Wu, F. T., R. J. Rau, and D. Salzberg, 1997: Taiwan orogeny: thin-skinned or lithospheric collision? Tectonophys., 274, 191-220.

Wu, Y. M., W. H. K. Lee, C. C. Chen, T. C. Shin, T. L. Teng, and Y. B. Tsai, 2000: Performance of the Taiwan Rapid Earthquake Information Release System (RTD) during the 1999 Chi-Chi (Taiwan) earthquake. Seismo. Res. Let., 71, 338-343. 